\title{
RESEARCH ON THE FRAMEWORK OF THE SMART CONSERVATION MANAGEMENT SYSTEM FOR THE HISTORIC CITY FUZHOU
}

\author{
Gong Zhang ${ }^{1}$, Yong Yang ${ }^{2}$, Zhongyuan Huang ${ }^{1}$, Gongli Li $^{1}$, Mingjie $\mathrm{Li}^{1}$, Zhe Wang ${ }^{1}$, Shaopeng Lin ${ }^{2}$ \\ ${ }^{1}$ Beijing Tsinghua Tongheng Urban Planning \& Design Institute, Beijing, China - (zhanggong, huangzhongyuan, ligongli, limingjie, \\ wangzhe.mc)@ thupdi.com \\ ${ }^{2}$ Fuzhou Historic City Management Committee, Fuzhou, China - yangyong625@163.com, 406927412@qq.com
}

\author{
Commission II, WG II/8
}

KEY WORDS: GIS, Smart City, Historic City, Cultural Heritage, Conservation Management System

\begin{abstract}
:
Historic cities, especially inhabited historic cities, are a special type of cultural heritage. Because of the expanding intension and extension of urban heritage, the rapid urbanization and the various stakeholders, the historic cities become much more complex nowadays. The need of GIS-based information systems for historic cities has never been greater. This paper introduces the research on the framework of the Smart Conservation Management System for the Historic City Fuzhou. It is an effort to explore an informatization way for historic cities. The needs of urban heritage itself, and the needs of different stakeholders should be respected. This system follows the principle of authenticity and integrity conservation, the coordination of conservation and sustainable development, the consideration of stakeholders, ease of use, extensibility, and security. The database should be fit for the construction of knowledge warehouse, be easy to collect and renew information. The module should be able to apply easily in everyday use situations, support smart decision making for the users. It is hoped that the research and the system will be referential for other historic cities.
\end{abstract}

\section{INTRODUCTION}

Historic towns/cities, especially inhabited historic towns/cities, are a special type of cultural heritage. Beyond their role as historical documents, they embody the values of traditional urban cultures (ICOMOS, 1987). In 1987, historic towns which are still inhabited were listed as a special type of world heritage for the first time (World Heritage Centre, 1987). In fact, as long ago as 1960s, the Ministry of Housing and Local Government organized a commission to study the conservation of historic centers of York, Manchester, Bath and Chichester, commissioned (Viscount, 1968). In China, a system of Listed Historic Cities of National Importance was established in 1980s, and 134 historic cities are on the present list.

Due to the complexity of the urbanization, socio-economic and cultural change, the variety of the stakeholders, conservation management is always a big challenge for these cities (Francesco and Ron, 2012). Recent years, several historic cities are planning to establish their own conservation management system (Mingxing and Chao, 2012), and some research has been done and achieved preliminary results, such as Arches by Getty \& WMF (Getty Conservation Institute and World Monuments Fund, 2019). This paper is based on the research, construction and implementation of the smart conservation management system (phase I) of Fuzhou, a listed Historic City of National Importance in China with a 2200 years' history. The entire research was commissioned by Fuzhou Historic City Management Committee, an agency of Fuzhou Municipal Government.

In the last 15 years, Fuzhou has made great achievements in conserving and revitalizing the historic city. Sanfangqixiang, a historic area in central city of Fuzhou which was included in China's tentative list for World Cultural Heritage nomination in 2012, won UNESCO Asia-Pacific Awards for Cultural Heritage Conservation in 2015. However, there're still lots of problems in managing the complex historic city, for example: the fragmentation of information, the lack of standards of data and process, low level of geo-informatization, low efficiency of coordinating different departments of the government, difficulty in analyzing the benefit of the investment in conservation, etc.

The management system adopted by Fuzhou is aiming to solve these problems, and provide the government, the public, the scholars, and other different stakeholders with a smart system to see, to learn, to share, to analyze, to make decisions, and to participating different activities in conserving this historic city. In phase I, we're focusing on the conservation management system for the government, and the need of sharing cultural heritage information with the public.

\section{DEMAND ANALYSIS}

Historic cities are among the most abundant and diverse manifestations of our common cultural heritage, shaped by generations and constituting a key testimony to humankind's endeavours and aspirations through space and time (Francesco and Ron, 2012). Management is fundamental to the conservation of historic cities. According to Article 23 of Principles for the Conservation of Heritage Sites in China, "the role of site management is to understand, promote and protect the site's values through providing long-term planning and vision, establishing policies and regulations, coordinating activities among departments, identifying and taking action to eliminate potential threats, controlling development in the buffer zones, liaising with stakeholders and local community, providing site staff with educational and training opportunities, regular maintenance of the site, providing quality exhibitions and interpretation, collecting and compiling archival documents, managing tourism, providing security, and ensuring sources of finance" (ICOMOS China, 2015). For this reason, the conservation management system should meet not only the needs of urban heritage, but also the needs of the stakeholders involved 
in the whole process. In China, the conservation of a historic city must cover the whole administrative region (Ministry of Housing and Urban-Rural Development of the PRC, 2019), so this system should have the ability to manage all urban heritage in Fuzhou.

\subsection{The needs of urban heritage}

The historic city compiles various urban heritage. According to Sustainable development of Urban historical areas through and active Integration within Towns, urban heritage comprises three main categories:

1) Monumental heritage of exceptional cultural value;

2) Non-exceptional heritage elements but present in a coherent way with a relative abundance;

3) New urban elements to be considered (for instance):

a) The urban built form;

b) The open space: streets, public open spaces;

c) Urban infrastructures: material networks and equipments.

(Francesco and Ron, 2012)

ICOMOS offers a broader concept - historic urban landscape in 2011. HUL includes "a wider context includes notably the site's topography, geomorphology, hydrology and natural features, its built environment, both historic and contemporary, its infrastructures above and below ground, its open spaces and gardens, its land use patterns and spatial organization, perceptions and visual relationships, as well as all other elements of the urban structure. It also includes social and cultural practices and values, economic processes and the intangible dimensions of heritage as related to diversity and identity" (Francesco and Ron, 2012).

While the urban heritage is not only a type of cultural heritage, but also an important role of sustainable development, the needs of the system should include the common requirement of heritage conservation and the sustainable development:

2.1.1 Documentation: Documentation is the fundamental work for heritage conservation. Because of the variety of the urban heritage, appropriate standards should be established for different types of urban heritage. In Fuzhou, survey and inventory of some type of urban heritage (such as historic buildings, cultural relics, registered old trees, etc.) commissioned by different departments have been done, and these standards are quite clear. Others (such as historic sites, historic streets, historic rivers, etc.) will always been documented when a conservation plan is making, and these recording formats are not standardized. So this system should try to set a database which is standardized and suitable for different urban heritage; a database which is capable to record information at different phase of the lifetime of heritage; and a database which is capable to exchange and synchronize information (such as property right information) with other systems.

2.1.2 Research and assessment: Research is the key process of conserving urban heritage. The assessment of the values is a process of selecting and connecting (Jie, 2019). As the intension and extension of urban heritage expanded, more researches and assessments need to be done. A tool is needed to help scholars and other stakeholders to analyse the geospatial and thematic relationship of different urban heritage easily, and to share information easily. A knowledge warehouse of the urban heritage (tangible and intangible) will be significant.
2.1.3 Authenticity, Integrity, Safety: These three are the most important for urban heritage. Besides documentation, research and assessment, management (including planning, implementing the conservation plans, monitoring, etc.) is quite significant. Since there're huge number of plans for the urban heritage of Fuzhou, a system showing all the plans in one map is needed. Traditional conservation plans need to be transformed into more structured, object-oriented formats, in order to support smart decision making. Monitoring using big data, RS, etc. will be expected.

2.1.4 Use: Most urban heritage is an asset with high value, appropriate use while ensuring its conservation will benefit the society and the owners. The regulation of use is set in the conservation plan, but whether it is appropriate while time changes should be monitored and assessed. A system which can record the change of use, the cost and benefit and can help stakeholders assessing it will be needed.

\subsection{The needs of stakeholders}

2.2.1 Authorities and agencies: They are the most important users. The main concerns are conserving and revitalizing the cultural heritages and balancing the benefits of different stakeholders. Their jobs include to set and maintain the list of conservation, to set and execute regulations, to decide and supervise the use of fiscal fund, to evaluate the result and to make modifications, to share information with other stakeholders, to control activities of different stakeholders, etc.

2.2.2 Property owners: The main concerns are the improvement or decline of the value or quality of their property, the benefit or constrain of conservation regulation or policy. They also care about the cultural value of their property and want to participate in relevant activities.

2.2.3 Business entities involved: Including the construction company, the commercial tenant, the tourism company involved in conserving and utilizing the historic city. The main concerns are the policies about subsidy and incentive, the regulations relative to their activities, the potential value of the cultural heritages, and the benefit of their activities.

2.2.4 The Public (including tourists): The main concerns are the information of the cultural heritages, the tourist route, the service facilities, and the feelings of the tour. They also care about whether the purchased goods are in compliance, whether they can complain about the illegal services of the commercial operation company or product.

\section{PRINCIPLES AND GOALS OF THE SYSTEM}

\subsection{Principles}

This system follows the principle of authenticity and integrity conservation, the coordination of conservation and sustainable development, the consideration of stakeholders, ease of use, extensibility, and security.

\subsection{Goals}

Based on these analyses, these goals are set for the system: 1) Form a digitalized asset library and conservation planning library of the whole historic city of Fuzhou, and provide tools of searching, analysing and renewal for stakeholders with different permissions. 
2) Provide the authorities with several managing tools to make supervision and approval of relative activities more efficient and less cost.

3) Provide several smart decision-making tools of fiscal fund use, policy optimization, and project selection for the authorities.

4) Provide knowledge map and other applications for the public;

5) Provide basic information and applications for tourism services;

6) Provide applications of public participation in conservation.

7) Provide monitoring tools for the authorities.

8) Set relative regulations and standards for sustainable use of this system.

\section{THE ARCHITECTURE AND MAIN MODULES}

\subsection{Architecture of the system}

The architecture of the system is showing in Figure 1. There're 4 layers in this system: application, service, data and infrastructure.

Smart Conservation Management System for the Historic City Fuzhou

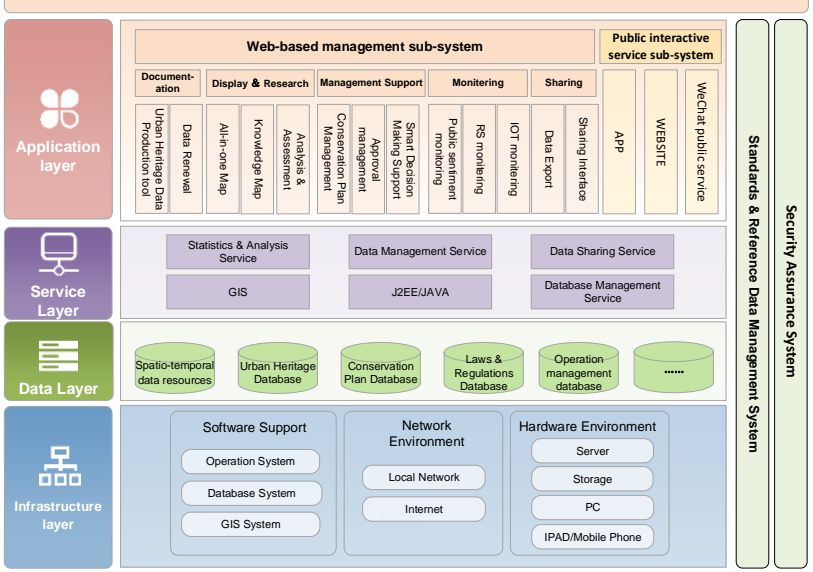

Figure 1. Architecture of the system

The main part in the application layer is a web-based management system, it meets the main needs of urban heritage and stakeholders, especially the authorities, which are documentation, display \& research, management support, monitoring and sharing. The needs of the public are supported by the public interactive service sub-system, including a website, APPs for iOS and android, and a WeChat service.

The service layer includes statistic \& analysis service, data management service, data sharing service, GIS service, J2EE/JAVA Service and database management service. They connect the application layer with the data layer.

There're several databases in this system. Maps, DEM, satellite images, and other spatial data in different time are stored in the spatio-temporal database. All the information about the tangible and intangible heritage are stored in the Urban heritage database. It's the most significant database in this system and will be constructed as a cultural heritage knowledge warehouse of the historic city Fuzhou. The conservation plan database and laws \& regulation database are structured database where the regulations about the urban heritages are stored. Operation management database $\log$ all the information about the users and the operations.

We also develop a standards and reference data management system to organize the standards and vocabularies. There's a security assurance system to manage the users, permissions and other security related issues.

The system requires these software to run: PostgreGIS 9.5, GeoServer 2.13.1, Windows Server2012.

\subsection{Database}

Since the spatio-temporal database is directly transferred the data from Digital Fuzhou on the E-government cloud, this paper is focusing on the urban heritage database and the conservation plan database:

4.2.1 Urban heritage database: There are several ways to categorize urban heritage, such as the ways of World Heritage (World Heritage Centre, 2017), and the ways defined by the laws and regulations made by the central government of China. This database should cover all the types of urban heritage in Fuzhou and make it a knowledge warehouse by creating relationships among the tangible urban heritage, the intangible heritage (including the memories of the public), and the values of the historic city. The database is designed as the schema showed in Figure 2. The categorization of the tangible urban heritage considers the different attributes of different types of heritage. Although some of them, such as the historic centre, contain others (historic sites, architecture heritage, etc.), they are considered as a separate type with their own attributes (such as the pattern, the function in this case). The relation of inclusion in space will easily be created in the spatio-temporal database.

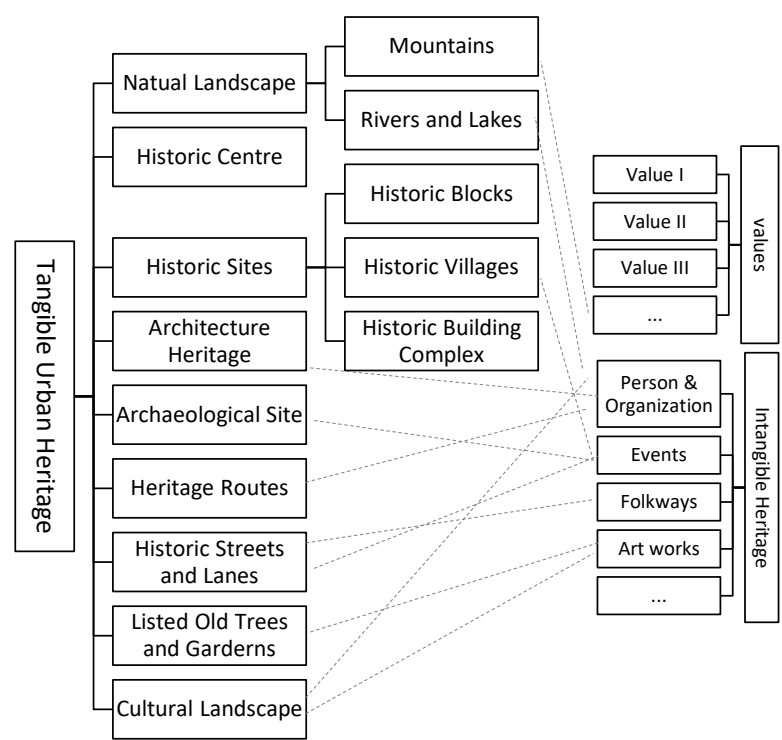

Figure 2. Schema of the urban heritage database

4.2.2 Conservation Plan database: Since there're huge number of urban heritage in Fuzhou, lot of conservation plans were prepared and approved. We do not just store these plans in pdf or word formats. We converted most of the plans into structured data. For example, we extracted the regulation of the buffer zone of the historic site, and created a field for it. With this database, smart management decision will be much easier. 


\subsection{Main module}

4.3.1 Display \& research: All-in-one Map module renders all the data of different types of urban heritages and the conservation zonings on the map of Fuzhou, making it easy to browse, to inquire, to statistic analyse (figure 3 ). Users can inquire any information of the urban heritage (figure 4), including all the attributes and the multimedia files, implement analysis including statistical analysis, aggregation analysis, etc. (figure 5,6).

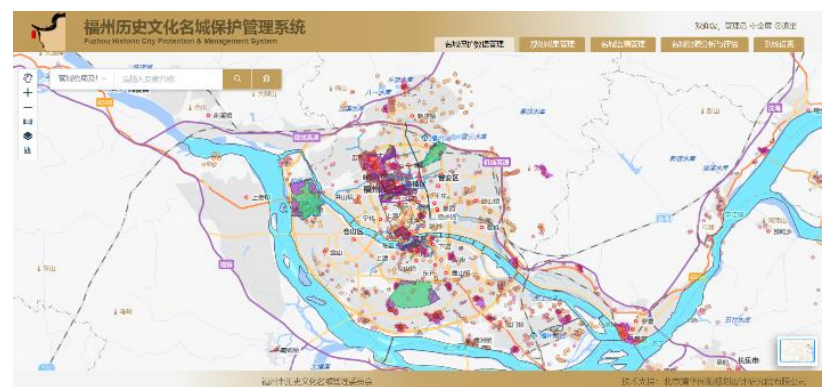

Figure 3. All-in-one Map rending all the urban heritage and conservation zoning of Fuzhou

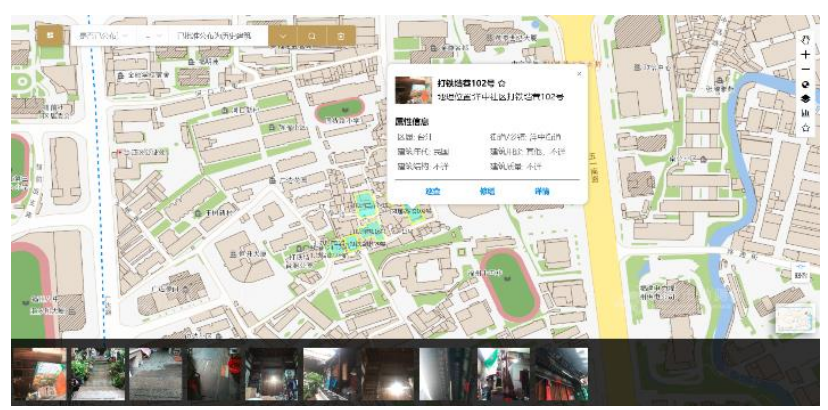

Figure 4. Inquiring the basic information and photos of a historic building

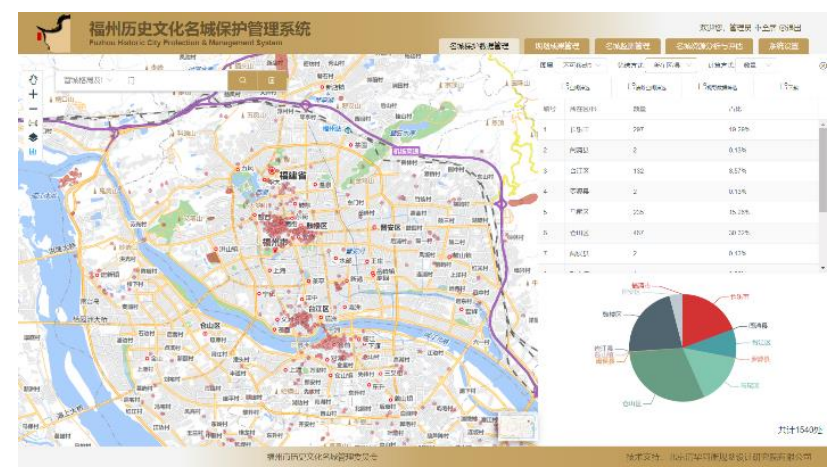

Figure 5. The statistical analysis of the cultural relics of Fuzhou

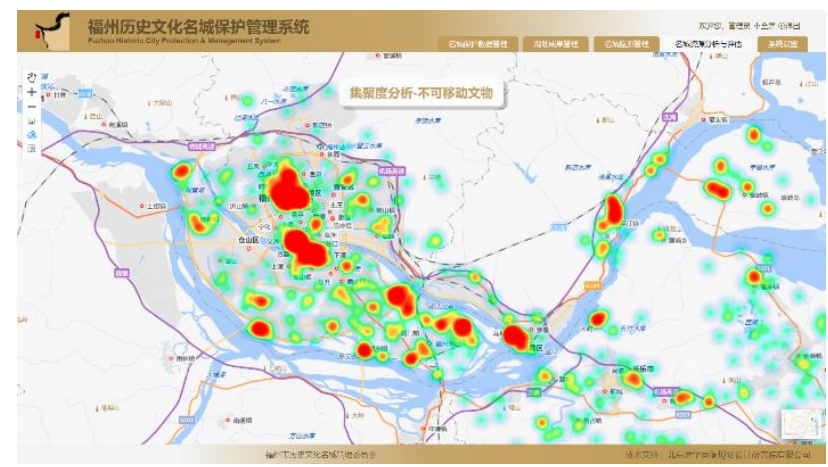

Figure 6. The aggregation analysis of the cultural relics
4.3.2 Documentation: A tool for converting various types of conservation plans, attributes of cultural heritages and other digital data into standard GIS data has been developed. It's also an important tool for renewing the data in the future. Another tool (including an app, and a program for PC) can help users to survey the historic sites and collect information easily with iPad (figure 7).

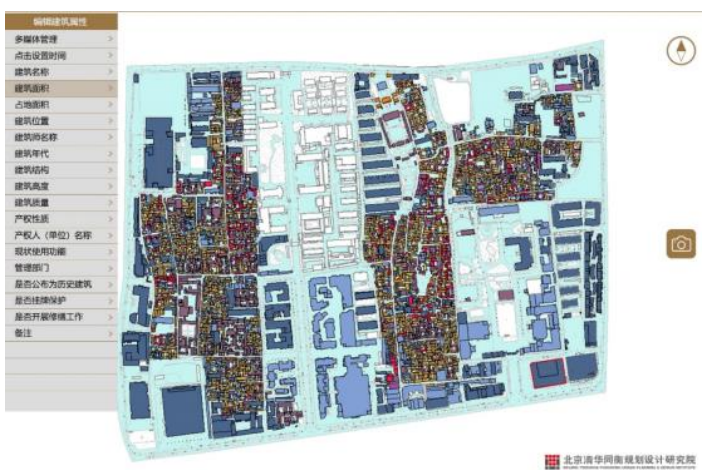

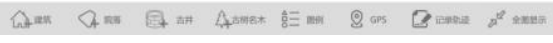

Figure 7. App for historic sites survey on iPad

4.3.3 Management Support: We converted all the traditional paper/word/CAD based conservation plan into GIS database. Managers can browse and inquire the zoning, regulation and other information of the plan on the map (figure 8). When the land boundary and proposal of a developing project is uploads to the system, a report will give to the user which tells whether the project will be constrained by any conservation plan, and the details of regulations.

The system also supports approval management of interventions related to urban heritage. Since lots of information (such as the cost and benefit, the threat, etc.) is stored in the database, heritage managers can analyse and evaluate the relevant quantitative indicators, then make a smarter decision. For example, by analyse the existing conditions, types and areas of properties, costs for conservation of specific type of historic buildings, the authority will get a wiser fiscal plan and a better strategy for conserving the historic buildings in Fuzhou.

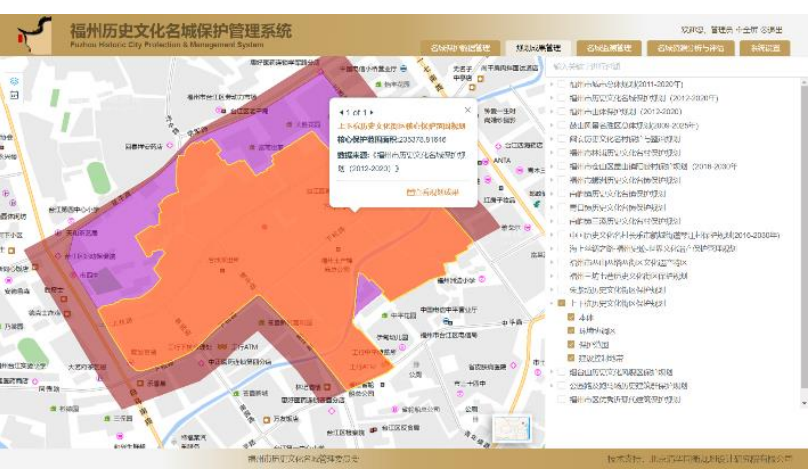

Figure 8. The conservation zoning of Shangxiahang Historic Site

4.3.4 Monitoring: With the monitoring APP we provided, local heritage managers can upload standard monitoring records on-site. Managers of city authority can browse, inquire and deal with the incidents reported by the local managers (figure 9).

In the next phase, authorities will be able to make a comparison of remote sensing change detection in conservation zone. With the support of spatio-temporal database provide by Digital 
Fuzhou, illegal construction in conservation zone will be easily discovered. The system will also be able to uses the technology of IoT, public sentiment monitoring to support highly efficient monitoring management of the cultural heritages in the next phase.

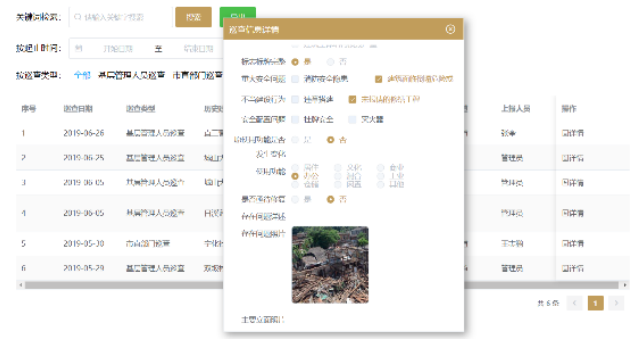

Figure 9. The monitoring information uploaded by the local manager of a historic building

4.3.5 Sharing: Because the system is deployed on the egovernment cloud and followed the informatization standard of Fuzhou, it's capable to share information with other departments. Users can also export the data and print out the archives, providing a traditional way for people who are not familiar with computers.

4.3.6 Public interactive service: The system includes a website, APPs for iOS and android, and a WeChat service for the public. People can browse the information of the urban heritage, news, activities of historic city Fuzhou and leave comments through Wechat, Website or the APP (figure 10).

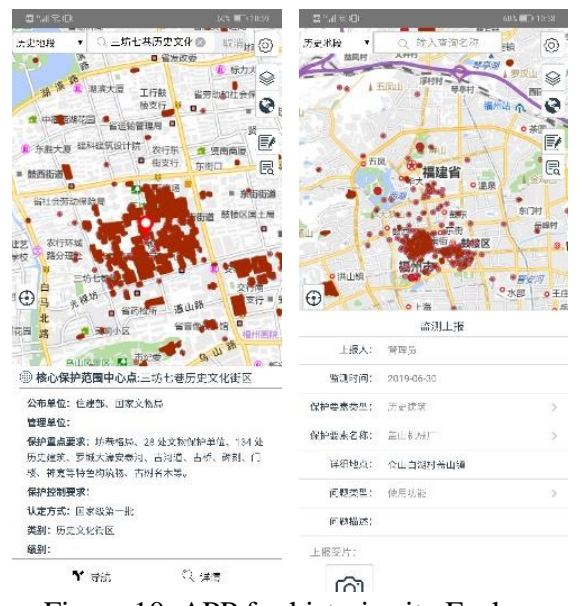

Figure 10. APP for historic city Fuzhou

\section{CONCLUSIONS}

Because of the expanding intension and extension of urban heritage, the rapid urbanization and the various stakeholders, the historic city becomes much more complex nowadays. The need of GIS-based information systems for historic cities has never been greater.

The conservation management of Fuzhou is an effort to explore an informatization way for historic cities. We should respect the needs of urban heritage itself, and the needs of different stakeholders. The system should follow the principle of authenticity and integrity conservation, the coordination of conservation and sustainable development, the consideration of stakeholders, ease of use, extensibility, and security. The database should be fit for the construction of knowledge warehouse, be easy to collect and renew information. The module should be able to apply easily in everyday use situations, support smart decision making for the users.

This system is not only a GIS based platform, it's also a system of regulations, policies and mechanisms supported by the platform. During the process of constructing the system, we dedicated ourselves to optimize the relative regulations, policies and mechanisms.

It is hoped that the research and the system will be referential for other historic cities.

\section{REFERENCES}

Francesco, B. and Ron, V.O., 2012. The Historic Urban Landscape: Managing Heritage in an Urban Century. WileyBlackwell, Chichester, pp. 209-216

Getty Conservation Institute and World Monuments Fund, 2019. Arches, Version 4.41. J. Paul Getty Trust and World Monuments Fund https://www.archesproject.org (1 June 2019)

ICOMOS China, 2015. Principles for the Conservation of Heritage Sites in China, ICOMOS China, Beijing, pp. 62-64.

ICOMOS, 1987. Washington Charter. ICOMOS, Washington D.C., pp. 1-3.

Jie, Z., 2019. On the settlement heritage and the construction of its value system. China Cultural Heritage, 2019(3), pp. 4-11.

Mingxing, H. and Chao, J., 2012. Research on Conservation Application System of Historic Cities Based on GIS. Southeast University Press, Nanjing, pp. 6-11.

Ministry of Housing and Urban-Rural Development of the PRC, 2019. Standard of conservation planning for historic city. China architecture \& building press, Beijing, pp. 1-6.

Viscount, E., 1968. York: A Study in Conservation. Her Majesty's Stationary Office, London.

World Heritage Centre, 1987. Operational Guidelines for the Implementation of the World Heritage Convention. UNESCO World Heritage Centre, Paris, pp. 6-8.

World Heritage Centre, 2017. Operational Guidelines for the Implementation of the World Heritage Convention. UNESCO World Heritage Centre, Paris, pp. 45-53. 